\title{
Emociones en educación infantil: perspectiva docente
}

DOI: $10.46932 / \mathrm{sfjdv} 2 \mathrm{n} 2-051$

Received in: january 1st, 2020

Accepted in: March 30th, 2020

\author{
Marta Mendez Montoya \\ Graduada Educación Infantil \\ Institution: RG Formación \\ Calle Rosalía de Castro, 44, 30107 Murcia \\ Marta Pérez Martínez \\ Graduada Educación Infantil \\ Institution: RG Formación \\ Calle Rosalía de Castro, 44, 30107 Murcia \\ Ana Ruiz Alonso \\ Graduada Educación Infantil \\ Institution: RG Formación \\ Calle Rosalía de Castro, 44, 30107 Murcia \\ Jose María Rabal Alonso \\ Profesor ISEN Centro Universitario \\ Institution: Universidad de Murcia \\ Calle Campus Universitario, 12, 30100 Murcia \\ E-mail: josemaria.rabal@um.es
}

\section{RESUMEN}

Tras el análisis de las emociones y educación emocional en la etapa de Educación Infantil, en varios artículos anteriores a este, exponiendo ejemplos de metodologías y actividades, consideramos de vital importancia conocer cuál es la percepción de los docentes sobre este tema a través de una entrevista semiestructurada con profesionales del ámbito de la Educación Infantil.

Palabras clave: Entrevista, percepción del docente, educación emocional, emociones en Educación Infantil, emociones en el aula de infantil.

\section{MARCO TEÓRICO}

Daniel Goleman quien, en 1995, define que la 'inteligencia emocional' es aquella que hace referencia a aprender, desarrollar y perfeccionar ciertas habilidades como el autocontrol, el entusiasmo, la empatía, la perseverancia y la capacidad para la automotivación.

Los discentes aprenden a reconocer las emociones, mediante gestos por ejemplo, pero no se suele profundizar en enseñar a los niños a expresar sus propios sentimientos, conocer los propios y reconocer los de los demás. 
Es indispensable que la educación no sólo enseñe a los niños y niñas materias o asignaturas como matemáticas, educación física, lenguaje... sino que también tenemos que mostrar el camino y enseñar otro tipo de valores a los más pequeños como la responsabilidad, el esfuerzo, el trabajo en equipo, espíritu crítico, la empatía, etc.

Para poder desarrollar estas capacidades en los más pequeños, trabajar la inteligencia emocional en las aulas es un buen primer paso.

Tal y como señala González (2020), la inteligencia emocional se ha aplicado en numerosos ámbitos y la educación no está exenta. Hasta hace pocos años el sistema educativo se había centrado en la adquisición de conocimientos cognitivos y había dejado fuera las emociones. Sin embargo, numerosos estudios consideran que los altos índices de abandono escolar se deben a que no se ha sabido entender y comprender las necesidades de muchos estudiantes y trabajar la educación emocional en las aulas sería un paso para evitar el fracaso escolar.

Por lo tanto, nos vamos a centrar en trabajar las emociones en edades comprendidas entre 3 y 6 años, puesto que es la edad más adecuada para llevar a cabo el desarrollo de las relaciones interpersonales, donde se trabajan varios aspectos del desarrollo integral del niño, propiciando la interconexión entre familia, comunidad y escuela.

Por ello, siguiendo a López Cassà (2005), se puede observar cómo señala la importancia de trabajar las emociones, ya que nos acompañan a lo largo de toda la vida. Como señala este autor, las emociones están presentes en nuestras vidas, desde que nacemos, juegan un papel relevante en la construcción de nuestra personalidad e interacción social. Además, las emociones intervienen en todos los procesos evolutivos: en el desarrollo de la comunicación, en el conocimiento social, en el procesamiento de la información, en el apego, en el desarrollo moral, entre otros aspectos, además de ser la principal fuente de las decisiones que tomamos diariamente.

Partiremos de las definiciones de los siguientes autores sobre las emociones como la de Bach y Darder (2002) que promueven que "las emociones derivan de sucesos internos o externos significativos y normalmente comportan algún tipo de alteración en el curso habitual de nuestra vida". (p.49). También, Goleman (1995) señala: "En mi opinión, el término emoción se refiere a un sentimiento y a los pensamientos, los estados biológicos, los estados psicológicos y el tipo de tendencias a la acción que lo caracterizan". (p.418)

Por otro lado, Rotger (2017), considera las emociones como reacciones psicofisiológicas que representan modos de adaptación a ciertos estímulos del individuo cuando percibe un objeto, persona, lugar, suceso o recuerdo importante, preparándonos para una reacción. 
La Educación Emocional es un proceso educativo que potencia el desarrollo integral del niño. Conocer y reconocer sus propias emociones y las de los demás proporcionará a los niños habilidades sociales y gestión adecuada de las mismas.

Aplicar la Educación emocional en el aula puede fomentar la responsabilidad, la empatía, el respeto, la escucha activa y la comunicación positiva, que ayudarán en el funcionamiento diario del aula mejorando el clima socioafectivo. Con la aplicación de la Educación Emocional en el aula, se pretende conseguir la gestión emocional adecuada y la validación de las mismas para los alumnos/as para mejorar sus experiencias emocionales, propias y colectivas.

Tras un estudio exhaustivo de las emociones y educación emocional en la etapa de Educación Infantil, exponiendo ejemplos de metodologías, actividades, técnicas... en artículos anteriores, hemos querido ir un paso más allá y conocer cuál es la percepción de los docentes sobre este tema.

Para ello, hemos realizado una entrevista semiestructurada, es decir, las preguntas estaban planificadas previamente y son las mismas para nuestros entrevistados, aunque cabe la posibilidad de realizar cuestiones sobre "la marcha", con el fin de enriquecer aún más el contenido a tratar.

El perfil del entrevistado (muestra) está relacionado con el ámbito educativo, concretamente en la etapa del segundo ciclo de Educación Infantil, siendo diversos docentes quienes están implicados en la educación emocional o trabajan directamente con las emociones en el aula. Dichas entrevistas las presentamos a continuación:

\section{ENTREVISTA NÚMERO 1. MAESTRO DE EDUCACIÓN INFANTIL}

1. En esta situación de pandemia en la que nos encontramos, ¿cree usted que las emociones se están trabajando en el aula? ¿Se dedica espacio y tiempo necesario, a que los alumnos puedan expresar sus sentimientos y poder así resolver sus conflictos emocionales?

Yo creo que sí, de hecho ahora más que nunca tanto por propia iniciativa de los profesores como por parte de la Consejería de Educación y Cultura de la Región de Murcia, la cual nos facilita programas emocionales para implantarlos en el aula, como por el ejemplo "Volvamos más cercanos".

En mi caso, por ejemplo, considero que sí que le dedico bastante tiempo debido a la importancia de trabajar las emociones desde las edades más tempranas y en esta situación de pandemia en la que nos encontramos. Ah y hay que trabajar para resolver los conflictos.

2. ¿Refleja nuestro sistema educativo actual el aprendizaje de las emociones? ¿Y concretamente en la etapa de Educación Infantil?

En el sistema educativo, las emociones no se reflejan como tal, en el currículo por ejemplo, ello no quiere decir que no se trabajen, sino que se trabajan de manera implícita en cada una de las áreas, al 
menos en mi caso. Esto se puede observar en que en dicho currículo se menciona que el niño se sienta feliz, desarrollando todos los aspectos, aquí por ejemplo no vemos que se refiere al aspecto emocional de manera explícita, pero sí implícita.

3. ¿Considera que la Educación se comienza a tratar desde el tejado de una casa en vez de sus cimientos?

Según mi experiencia, yo creo que no, porque para considerar la educación emocional, primero hay que enseñarle al alumnado cuáles son las emociones, etc. No les pedimos que el primer día, ya nos digan cómo se sienten, sino que vamos enseñándoles la relación de cada emoción con los sentimientos, como exteriorizarlos, gestionarlos...

4. ¿Realmente se implican y coordinan todos los sectores para que un alumno pueda obtener un beneficio de nuestro sistema educativo?

Todos los sectores no, porque los inspectores y la consejería de educación no vienen a consultar a los maestros y ponen las leyes que crean convenientes sin tener en cuenta las situaciones de las aulas. A la vista está que continuamente se cambian los decretos por diversos errores o modificaciones.

5. ¿Se respetan realmente los intereses de los alumnos para llevar a cabo un proceso de enseñanza y aprendizaje positivo?

Intentamos que así sea. A veces, no se pueden atender a los intereses de toda la clase, pero sí de la gran mayoría.

6.¿Qué consideración tienen los docentes acerca de trabajar la educación emocional en las aulas?

Muy buena, es un tema primordial y ahora más que nunca. Sobre todo, la consejería ha hecho mucho hincapié en esto, ayudando a los profesores a abordar estos aspectos para poder desarrollar aspectos emocionales en la pandemia, facilitando charlas y cursos de formación y didáctica emocional al profesorado.

7. ¿Cómo es la continuidad de trabajar la educación emocional entre la etapa de Educación Infantil y Primaria?

En mi opinión no hay una continuidad, al menos aparentemente, es cierto que en algunas ocasiones en la que los alumnos lo requieran sí que habría esa continuidad.

8. ¿Cómo deberían tratarse estas capacidades/competencias emocionales en el aula de Educación Infantil?

En mi caso, las llevó a cabo de forma transversal, que creo que es como habría que desarrollarlas, a lo largo de todo el día, y presentes en todas las áreas.

9. ¿Es posible que la dificultad de llevar este tipo de programas a la práctica sea el origen del desconocimiento de los profesores? 
Yo creo que no, porque es un tema muy conocido sobre todo en infantil, además se le está dando mucha publicidad al tema de las emociones, por ejemplo con el programa mencionado anteriormente "Volvamos más cercanos", se nos aporta material para llevarlo al aula, tanto para educación infantil como para primaria. La dificultad radicaría en la programación, que es cierto que no hay tiempo material. Actualmente estamos tan obsesionados con la lectura y la escritura que se nos olvida lo primordial como son las emociones, algo básico para el desarrollo personal de los alumnos.

10. ¿Qué le ha llevado a implicarse en el trabajo de la Educación Emocional?.

Son varios los motivos que me han implicado en la educación emocional, algunos de ellos son: la publicidad, el conocimiento, los compañeros, la coordinación así como cantidad de material de fácil acceso y adaptada.

11. ¿Conoce alguna metodología innovadora para trabajar las emociones? ¿Qué cauces ha seguido para aprenderla?

No conozco ninguna metodología innovadora como tal, pues considero que ya hay pocos elementos innovadores sobre las emociones. Uno de los que yo utilizo es trabajarlas a través de cuentos infantiles, ya que hay mucho material y no hay que utilizar siempre el de "El monstruo de los colores".

Otro programa emocional que conozco y de hecho lo recomiendo es el de "El programa de María Dolores Hurtado", en el que se abarcan los niveles desde educación infantil hasta educación secundaria. 12. ¿Cree que estamos retomando aprendizajes y estrategias que ya se proponían en la Escuela Nueva y simplemente le hemos añadido un nombre más motivador?

Yo considero que no, ya que nunca se les ha dado importancia a las emociones como tal, el trabajo más relacionado con las emociones que se trabajaban anteriormente se basaban en resolver los conflictos, pero no la causa que origina el conflicto, que es lo básico que se trabaja actualmente con las emociones, es decir, lo que produce la emoción, por ejemplo la rabia, viene de los celos, envidia...

13. Cuando comenzó a implicarse en la educación emocional, ¿qué expectativas tenía?, ¿se han cumplido?, ¿Ha notado mejoría en sus alumnos, a partir de trabajar la educación emocional con ellos?

El primer contacto que he tenido con la educación emocional fue en una charla que le dieron a mi hijo sobre la resolución emocional para resolver conflictos. Esta charla se llevó a cabo en la escuela de padres, y a partir de ahí realicé varios cursos empezando a interesarme cada vez más en este tema.

$\mathrm{Si}$, se pueden observar varias mejoras, pero sobre todo el mejor dominio y control emocional, así como la reducción de los conflictos agresivos.

14. ¿Cómo era usted antes de no implicarse en la educación emocional y cómo es ahora? 
Antes era un maestro tradicional y ahora soy más innovador y permisivo. Prestando más valor a las emociones que a los elementos cognitivos, puesto que en educación infantil es lo básico que deben construir para posteriormente poder desarrollar los elementos cognitivos.

15. ¿Qué consejos nos puede aportar como futuros docentes?

Una buena educación emocional, es la base de unas buenas futuras relaciones sociales y un desarrollo armonioso y total como persona, para poder formar a los alumnos en una actitud de cuidado y respeto emocional.

\section{ENTREVISTA NÚMERO 2. MAESTRA DE EDUCACIÓN PRIMARIA}

1. En esta situación de pandemia en la que nos encontramos, ¿cree usted que las emociones se están trabajando en el aula? ¿Se dedica espacio y tiempo necesario, a que los alumnos puedan expresar sus sentimientos y poder así resolver sus conflictos emocionales?

La educación siempre tiene un componente emocional, en cuanto se realiza de persona a persona y las relaciones diarias que se producen en las aulas siempre están influidas por las emociones.

En esta situación de pandemia en la que nos encontramos actualmente, y en la que hemos pasado por varias fases en cuanto a la relación con los alumnos se refiere (no olvidemos la suspensión de las clases y la educación telemática) la vuelta a las aulas ha ido marcada por una progresión que busca parecerse en la máximo posible a la situación que teníamos anterior a la COVID-19.

Esa búsqueda de la estabilidad, además de los componentes curriculares eminentemente escolares, también influye en las emociones. El miedo al contagio, la inseguridad, el exceso de higiene, la falta de contacto, el distanciamiento... comenzaron a principios de la educación presencial como una gran muralla, a la que poco a poco nos hemos ido acostumbrando.

A esta capacidad de adaptación de alumnos y maestros, hemos de añadir programas centrados en las emociones, como el programa "Volvamos más cercanos" que ha sido creado por la Consejería de Educación de la Región de Murcia y en el que se establecen una serie de estrategias y herramientas para facilitar la vuelta a las aulas.

Pregunta extra. ¿Cree usted que con la situación actual de la pandemia, estamos deshumanizando ciertas actitudes que pueden ser beneficiosas para los niños y niñas en edad escolar, y sobre todo en Educación Infantil?

No creo que estemos "deshumanizando" la educación, pues para educar en emociones y valores, no es estrictamente necesario el contacto físico o una cara descubierta sin mascarilla. Podemos mostrarnos cercanos a nuestros alumnos a la vez que mantenemos las normas socio-sanitarias adecuadas, la clave está en lo que somos capaces de transmitirles y mostrarles, no en lo cerca que estemos unos de otros. 
Por otro lado, es cierto, que ciertas normas de higiene, las restricciones a la hora de compartir, de jugar, etc. pueden influir en cómo se ven los niños dentro de la escuela, y por lo tanto, en cómo les afecta emocionalmente.

2. ¿Refleja nuestro sistema educativo actual el aprendizaje de las emociones? ¿Y concretamente en la etapa de Educación Infantil?

(Voy a contestar en Primaria porque el currículo de Infantil no lo conozco muy bien)

Es evidente que el mecanismo legal que regula los aprendizajes en Educación Primaria (Leyes, Reales Decretos y Decretos), si bien se preocupa de que el alumnado se desarrolle no solo en los aspectos puramente académicos, sino que pretende la adquisición de todo clase de competencias que le permitan desarrollarse como persona y se desarrolle en sociedad de manera satisfactoria, aunque aborda los valores sociales y los elementos transversales, deja fuera de todo aprendizaje reglado tanto el aprendizaje como la gestión de las emociones.

3. ¿Considera que la Educación se comienza a tratar desde el tejado de una casa en vez de sus cimientos?

No considero que el problema sea por dónde comienza la Educación. En mi opinión uno de los grandes problemas reside en la subjetividad de los procesos educativos, es decir, como he comentado anteriormente la educación es un proceso personal y por lo tanto subjetivo; de ahí que la personalidad de alumnos, y sobre todo de los docentes, termine influyendo de manera determinante en el proceso.

Respecto a las emociones, no cabe duda que la sensibilidad personal, las experiencias previas, incluso la situación personal de cada docente influye en cómo transmite y enseña la gestión de los sentimientos y las emociones y esto pasa por no estar regulada en ningún sentido.

4. ¿Realmente se implican y coordinan todos los sectores para que un alumno pueda obtener un beneficio de nuestro sistema educativo?

En la mayoría de los casos, la coordinación tanto vertical como horizontal, está garantizada en los centro educativos.

La coordinación con las familias, que es un aspecto esencial en el desarrollo emocional de un niño, no siempre está asegurada, ya que existen barreras, en la mayoría de los casos culturales. Esta falta de fluidez en la coordinación, perjudica enormemente al niño o la niña, que en ocasiones, puede recibir mensajes contradictorios en uno u otro lugar.

5. ¿Se respetan realmente los intereses de los alumnos para llevar a cabo un proceso de enseñanza y aprendizaje positivo?

La base de muchas metodologías modernas, como el Aprendizaje Basado en Proyectos, la gamificación, etc. tienen su base en partir de los intereses del alumnado, lo cual hace que la motivación 
hacia el aprendizaje sea mayor y por lo tanto, aumentan las probabilidades de éxito escolar y aprendizaje significativo.

6. ¿Qué consideración tienen los docentes acerca de trabajar la educación emocional en las aulas?

Lamentablemente, al hablar de educación emocional, apelamos a la importancia que cada docente concede al tema y al tiempo que personalmente decide invertir en su aula al tratar la emociones.

Además de ellos, el área de educación en valores, regula contenidos relacionados con el autoestima y el autoconcepto, elementos fundamentales en la educación emocional, pero los que suponen una ínfima parte de la asignatura, que además solo es cursada por aquellos que no eligen la religión católica en Educación Primaria.

Por suerte, cada vez más, los centros están preocupados por esta parte esencial de la formación del individuo y crecen los planes y proyectos de centro en los que se dedican al trabajo de las emociones. También son más los docentes que se preocupan por este aspecto y se forman de forma autónoma, o en algunos cursos ofrecidos por el centro de profesores y recursos para abordar de manera efectiva estos aspectos en el aula.

7. ¿Cómo es la continuidad de trabajar la educación emocional entre la etapa de Educación Infantil y Primaria?

La transición entre Educación Infantil y Primaria, siempre es un paso complicado por los cambios tan grandes que se producen en el entorno y la estructura educativa de los niños y niñas.

La legislación vigente regula cómo ha de ser esta transición y centros y docentes se esfuerzan por hacer el tránsito de la manera menos traumática para el alumnado.

Además, y volvemos a la intención del docente, los maestros de los primeros cursos de Primaria, se preocupan, en su mayoría, por que exista una continuidad en la educación emocional y de valores que se ha ido transmitiendo desde el inicio de la escolarización de los discentes.

8. ¿Cómo deberían tratarse estas capacidades/competencias emocionales en el aula de Educación Infantil?

La educación emocional tiene diferentes formas de ser abordada, pero parece evidente pensar que para los niños y niñas más pequeños ha de partirse de la realidad propia, de sus propias vivencias, los sucesos de su entorno, y ofrecerles estrategias que les permitan expresar esas emociones y mecanismos de regulación de las que puedan resultar negativas. En este sentido existen multitud de recursos basados en pictogramas, colores para representar las diferentes emociones, semáforos de conducta...

9. ¿Es posible que la dificultad de llevar este tipo de programas a la práctica sea el origen del desconocimiento de los profesores? 
En mi opinión no es difícil llevar a cabo en el aula un programa sobre emociones. Los problemas residen en:

- La falta de organización curricular, ya que las exigencias de lo establecido curricularmente impiden un desarrollo de un programa emocional amplio, completo y por lo tanto, efectivo.

- La falta de formación del profesorado, que aunque de forma autónoma algunos decidan formarse, no todos los docentes poseen los conocimientos necesarios y esto conlleva a que no se pueda plantear un programa emocional con una continuidad a lo largo de toda la escolarización, pues pasarán muchos profesores por la vida escolar del alumnado y será cuestión de "suerte" que estén preparados e interesados en este tema, o no.

\section{0. ¿Qué le ha llevado a implicarse en el trabajo de la Educación Emocional?}

Para mi la educación emocional es una parte muy importante en el desarrollo de los niños y niñas. Para ser futuros "ciudadanos del mundo", los conocimientos matemáticos o lingüísticos pueden ser importantes, pero la gestión que hagan de sus sentimientos y sus emociones les puede suponer la diferencia entre el éxito o el fracaso.

Como norma general esta educación emocional se deja a merced de la suerte, del currículum oculto o de las experiencias que niños y niñas tengan la suerte o la desgracia de experimentar en su vida, pero pocas veces se considera, que se puede aprender a gestionar las emociones y que lograr este control sobre ellas va a dar lugar a personas emocionalmente sanas, que se desarrollarán en sociedad de manera satisfactoria.

11. ¿Conoce alguna metodología innovadora para trabajar las emociones? ¿Qué cauces ha seguido para aprenderla?

Conozco el Coaching Educativo, que se basa en el desarrollo de la inteligencia emocional para provocar un aprendizaje positivo y significativo. En esta metodología se implica a la familia, y se trabaja con ella para que el desarrollo emocional continúe en todos los ámbitos de la vida de los niños y niñas.

También el PNL, estaría enfocado al trabajo emocional del alumnado al influir en sus procesos neurológicos a través de un lenguaje positivo.

12.¿Cree que estamos retomando aprendizajes y estrategias que ya se proponían en la Escuela Nueva y simplemente le hemos añadido un nombre más motivador?

Creo que la educación emocional no es ningún invento del siglo XXI, sino que es algo que se venía haciendo no desde la escuela nueva, sino desde que la educación es educación; es decir; como llevo diciendo varias veces, al ser la educación un intercambio interpersonal, está inevitablemente influido por las emociones, y ya sea de forma consciente a través de un programa o de forma inconsciente a través de los actos docentes, la emociones siempre han tenido un papel muy importante en la escuela. 
Si que es cierto, que a partir de la Escuela Nueva, y de investigadores y autores educativos que comienzan a dar relevancia a los aspectos más personales de los alumnos y es a estudiar cómo estos afectan en el aprendizaje, se han ido desarrollando teorías y metodologías que ponen cada vez más en valor el desarrollo de la inteligencia emocional y la necesidad de enseñarla en la escuela.

13. Cuando comenzó a implicarse en la educación emocional, ¿qué expectativas tenía?, ¿se han cumplido?, ¿Ha notado mejoría en sus alumnos, a partir de trabajar la educación emocional con ellos?

Como cada vez que surge la oportunidad de aprender sobre algo nuevo, mi intrusión con el desarrollo de la inteligencia emocional ha sido progresivo. Desde que empecé a leer y a investigar sobre algunas actividades que se podían realizar en el aula, he buscado la ocasión de trabajarlas con los alumnos. Las expectativas, cuando uno se implica en una "pequeña revolución metodológica" en el aula, siempre son altas, y no siempre se tiene resultados cien por cien satisfactorios.

Lo que sí me gustaría resaltar, es que tras un periodo prolongado de tiempo (tres años de continuidad con los alumnos) y sin trabajar todo lo que me habría gustado respecto al desarrollo de la inteligencia emocional, los resultados son visibles en la gran mayoría de ellos, y el ver cómo son capaces de autorregular su conducta, o gestionar una emoción concreta en un momento, escuchar su capacidad de reflexión, o la forma de aconsejar a un compañero sobre un hecho que le ha podido afectar emocionalmente, es muy gratificante como maestra implicada y convencida en la enseñanza de las emociones en el aula.

\section{4. ¿Cómo era usted antes de no implicarse en la educación emocional y cómo es ahora?}

Aunque siempre me he considerado una persona sensible y empática, a raíz de mi inquietud por el desarrollo de las emociones en el aula, y de la puesta en marcha de programas relacionados con ellas a nivel de centro, la perspectiva con la que intento transmitir estos conocimientos a los alumnos y alumnas ha cambiado.

Si bien siempre he pretendido aquello de "formar buenas personas", la información sobre los procesos emocionales, el conocimiento sobre las emociones y las herramientas para la gestión de las mismas, permiten el tránsito de las buenas intenciones a las buenas prácticas, y aunque indudablemente es largo el camino que queda por recorrer y las cosas que quedan por aprender, los resultados empiezan a ser más visibles y satisfactorios.

\section{5. ¿Qué consejos nos puede aportar como futuros docentes?}

Pues no se si me atrevería a dar consejos, pues parece que eso corresponde a sabios o expertos, y esa no soy yo... pero si pudiera decir algo que pueda servir de reflexión es que tenemos en nuestras manos a niños expectantes por aprender a vivir, que lo curricular es importante, pero más importante es ser feliz, y si somos capaces de educar niños y niñas emocionalmente sanos, felices, estables, niños y niñas que 
saben empatizar, adaptarse a los cambios y gestionar sus sentimientos, le estamos dando las estrategias para que en su vida adulta se puedan desarrollar con plenitud en todos los aspectos que ello implica.

\section{ENTREVISTA NÚMERO 3. ESPECIALISTA EN PEDAGOGÍA TERAPÉUTICA}

1. En esta situación de pandemia en la que nos encontramos, ¿cree usted que las emociones se están trabajando en el aula? ¿Se dedica espacio y tiempo necesario, a que los alumnos puedan expresar sus sentimientos y poder así resolver sus conflictos emocionales?

Al inicio del curso escolar, la Consejería de Educación y Cultura de la Región de Murcia estableció un periodo con una duración de una semana, en la que se desarrolló el programa "Volvamos más cercanos", para que se desarrollará en el aula, pero una vez terminada esa semana, no se han seguido desarrollando programas emocionales, al menos en el centro donde ejerzo. Además de trabajar estos contenidos, también se promulgó empezar con los contenidos del tercer trimestre del curso pasado, así como medidas higiénicas y competencia digital.

En mi caso, en el aula de 5 años sí se están desarrollando actividades emocionales en general, pero no es debido al Covid, sino porque hay niños que lo necesitan.

Otro aspecto que se desarrolla en el centro es el taller de habilidades sociales, donde se trabajan aspectos emocionales con alumnos de varias edades.

2. ¿Refleja nuestro sistema educativo actual el aprendizaje de las emociones? ¿Y concretamente en la etapa de Educación Infantil?

No, es un aspecto que se tendría que trabajar más, ya que muchos profesores no las trabajan si no se expone explícitamente en el currículo.

En mi centro, por ejemplo, en 5 años he propuesto que las emociones se incluyan en la asamblea para que así se trabajen de manera diaria, de modo que se relacionen a diario cómo se sienten y lo relacionen con las emociones del monstruo de los colores.

3. ¿Considera que la Educación se comienza a tratar desde el tejado de una casa en vez de sus cimientos?

No, puesto que las emociones se comienzan a trabajar cuando se observa algún problema, ya sea conductual o emocional, sino que de manera general no se trabajan, al menos desde el comienzo de la escolarización.

4. ¿Realmente se implican y coordinan todos los sectores para que un alumno pueda obtener un beneficio de nuestro sistema educativo?

No, falta la coordinación y la sensibilidad de algunos sectores, profesionales y docentes, así como la falta de formación para detectar los problemas sobre todo emocionales. 
5. ¿Se respetan realmente los intereses de los alumnos para llevar a cabo un proceso de enseñanza y aprendizaje positivo?

Se atiende más a lo que establece el currículum y con esto me refiero a los libros escolares que se siguen para llevar a cabo la programación, que a los propios intereses del alumnado.

6. ¿Qué consideración tienen los docentes acerca de trabajar la educación emocional en las aulas?

Depende del docente, pero sobre todo depende de la sensibilidad para poder detectar las necesidades de los alumnos y a través de ello trabajar las emociones. Ejemplificando esto, me refiero a que si yo soy una persona sensible y veo que hay niños que necesitan trabajar las emociones, pues lo trabajaré, tanto si es a nivel de aula, de un pequeño grupo (como sería el caso del taller de habilidades sociales) o a nivel personal.

La mayoría de los docentes consideran que es importante pero falta formación y tiempo en el caso de primaria, debido a los contenidos que marca el currículum y no da tiempo a trabajar. Anteriormente se contaba con una hora semanal de acción tutorial, que podría venir bien para trabajar esos aspectos, pero ahora la han eliminado. Aunque esto no quita que las emociones se tienen que trabajar de manera transversal, pero como ya he explicado, a penas hay tiempo para ello.

7. ¿Cómo es la continuidad de trabajar la educación emocional entre la etapa de Educación Infantil y Primaria?

No hay continuidad, a menos que se detecte la necesidad y el maestro lo traslade a los especialistas si es algún problema constante y fuerte, y en ese caso ya dependería del maestro de educación primaria, siguiendo las recomendaciones del especialista si incluye la educación emocional en la clase o no.

8. ¿Cómo deberían tratarse estas capacidades/competencias emocionales en el aula de Educación Infantil?

En la asamblea, en la primera hora de la mañana como viene el alumnado al aula, también durante el patio y al finalizar la jornada escolar. Además de tratarse de forma diaria aprovechando los conflictos que puedan surgir en las aulas.

Trabajarlo de manera diaria nos puede ayudar a detectar posibles problemas, aprovechando ese espacio y tiempo para la atención más que para el desarrollo de dichas actividades.

9. ¿Es posible que la dificultad de llevar este tipo de programas a la práctica sea el origen del desconocimiento de los profesores?

Desde mi punto de vista considero que más que la dificultad, sería la dejadez porque hay programas como "El programa arco iris" que plantea actividades de infantil, primaria y secundaria. 
Por lo tanto considero que no se lleven programas emocionales al aula por la dificultad de implantarlo más que por el desconocimiento, porque hay mucha información, se debe más a la predisposición que exista para dejar espacio y tiempo para desarrollarlo

10. ¿Qué le ha llevado a implicarse en el trabajo de la Educación Emocional?

Debido a mi especialidad, es un tema que he tratado desde siempre, sobre todo a partir de tener en cuenta las necesidades de los alumnos, he ido formándome cada vez más con el objetivo de ir planteando actividades a lo largo del curso para trabajar las emociones.

11. ¿Conoce alguna metodología innovadora para trabajar las emociones? ¿Qué cauces ha seguido para aprenderla?

La metodología "El arco iris" de Ana Pintado, la conozco a través de mi formación y la predisposición que muestra la conserjería en ella, pues está interesada en implantar más tiempo para desarrollar estas emociones. Además creo que se debería empezar desde la formación del centro y del profesorado para ir implantando actividades.

12. ¿Cree que estamos retomando aprendizajes y estrategias que ya se proponían en la Escuela Nueva y simplemente le hemos añadido un nombre más motivador?.

$\mathrm{Si}$, se pretende que se desarrollen esos aprendizajes y estrategias cambiandole el nombre y actualizando la metodología, también ahora se llevan más a la práctica, sobre todo temas emocionales debido a que la gente está más sensibilizada.

13. Cuando comenzó a implicarse en la educación emocional, ¿qué expectativas tenía?, ¿se han cumplido?, ¿Ha notado mejoría en sus alumnos, a partir de trabajar la educación emocional con ellos?

Siempre he considerado necesario trabajar la educación emocional, imagino que debido a mi especialidad. Las expectativas que tenía sí que se han cumplido, pues entraba a clases donde no se trabajaban y veía la necesidad de buscar un hueco para trabajar esa parte emocional, incluso darle prioridad. También veía la necesidad de sacar de la clase a algún niño si anímicamente no estaba bien y ayudarlo a exteriorizar las emociones para poder resolver el conflicto entre los dos.

En algunos si se nota cierta mejoría sobre todo a la hora de expresarse en el tema emocional, ya que considero que es el aspecto que más les cuesta generalmente, exteriorizar las emociones.

14. ¿Cómo era usted antes de no implicarse en la educación emocional y cómo es ahora?

Siempre he estado implicada en estos aspectos.

15. ¿Qué consejos nos puede aportar como futuros docentes?

La formación continua en este aspecto, para poder desarrollarlas en las aulas desde el principio y con total naturalidad. 


\section{ENTREVISTA NÚMERO 4. ESPECIALISTA EN EDUCACIÓN FÍSICA}

1. En esta situación de pandemia en la que nos encontramos, ¿cree usted que las emociones se están trabajando en el aula? ¿Se dedica espacio y tiempo necesario, a que los alumnos puedan expresar sus sentimientos y poder así resolver sus conflictos emocionales?

No, se trabajan algunos contenidos pero no del todo, un nivel medio, no lo suficiente. También depende de los cursos y las características del alumnado. Se dedica el tiempo cuando ocurre la situación si no se dan conflictos no se trabajan.

2. ¿Refleja nuestro sistema educativo actual el aprendizaje de las emociones? ¿Y concretamente en la etapa de Educación Infantil?

Yo creo que no, estamos iniciandonos en ese proceso.

3. ¿Considera que la Educación se comienza a tratar desde el tejado de una casa en vez de sus cimientos?

Considero que se trabaja desde los cimientos, porque primero hay que enseñarle qué, cuáles, cómo... son las emociones, y una vez que se conocen estos aspectos, podemos comenzar a trabajar con ellas de una manera más dinámica

4. ¿Realmente se implican y coordinan todos los sectores para que un alumno pueda obtener un beneficio de nuestro sistema educativo?

Si se coordinan para aspectos diarios de la educación por ejemplo proyectos, planes, horarios, normativa, etc pero no se coordinan en tema emocional.

5. ¿Se respetan realmente los intereses de los alumnos para llevar a cabo un proceso de enseñanza y aprendizaje positivo?

No, es muy difícil atender a los 25 alumnos con intereses diferentes dentro de un mismo aula. Además de los intereses de los alumnos, habría que tener en cuenta el tipo de inteligencia que tiene cada alumno, pudiendo profundizar en las inteligencias múltiples de Howard Gardner

6. ¿Qué consideración tienen los docentes acerca de trabajar la educación emocional en las aulas?

Considero que la mayoría considera que es importante trabajar la educación emocional empezando en edades tempranas, pero sobre todo creen que es importante desarrollar esta educación en edades más avanzadas como podría corresponder a la etapa de la pre-adolescencia.

7. ¿Cómo es la continuidad de trabajar la educación emocional entre la etapa de Educación Infantil y Primaria?

Suponiendo que se trabaje la educación emocional en Educación infantil, que desde mi punto de vista no se trabaja todo lo que debería, considero que en el primer ciclo de Educación Primaria sí que hay posibilidad de que se trabaje, después se centra más en trabajar el contenido. 
8. ¿Cómo deberían tratarse estas capacidades/competencias emocionales en el aula de Educación Infantil?

Considero que se podría elegir un día a la semana y trabajar en ese día las emociones tanto de manera explícita como tema transversal.

9. ¿Es posible que la dificultad de llevar este tipo de programas a la práctica sea el origen del desconocimiento de los profesores?

$\mathrm{Si}$, entre otros motivos, también habría que tener en cuenta la gran cantidad de contenidos y materia que hay que trabajar en las aulas.

10. ¿Qué le ha llevado a implicarse en el trabajo de la Educación Emocional?

Tras investigar y ver formas de trabajar diferentes y más beneficiosas.

11. ¿Conoce alguna metodología innovadora para trabajar las emociones? ¿Qué cauces ha seguido para aprenderla?

Las inteligencias múltiples, porque a través de ellas puedes ir trabajando distintas emociones, además de poder atender a los intereses del alumnado.

12. ¿Cree que estamos retomando aprendizajes y estrategias que ya se proponían en la Escuela Nueva y simplemente le hemos añadido un nombre más motivador?

Desde mi punto de vista, considero que no, porque nunca ha interesado el tema emocional de los alumnos, y aún considero que se sigue sin prestarle mucha atención.

13. Cuando comenzó a implicarse en la educación emocional, ¿qué expectativas tenía?, ¿se han cumplido?, ¿Ha notado mejoría en sus alumnos, a partir de trabajar la educación emocional con ellos?

No, no he cumplido con totalidad las expectativas que tenía, porque para desarrollar verdaderamente la educación emocional hay que conocer mucho al alumnado. En cambio, sí que he notado mejoría implantando dichos aspectos.

14. ¿Cómo era usted antes de no implicarse en la educación emocional y cómo es ahora?

Desde mi punto de vista, considero que yo no he cambiado nada mis percepciones ni mi forma de ser, lo que he cambiado es el sistema de implantar la educación.

15. ¿Qué consejos nos puede aportar como futuros docentes?

Que sigamos formándonos en esta metodología, puesto que es más activa y cercana al alumnado.

\section{RESULTADOS}

En relación a la pregunta número 1, que trata sobre el trabajo de las emociones en el aula, su dedicación y si se establece un espacio y tiempo determinado para llevarlas a cabo en esta etapa y etapas posteriores los entrevistados número 1, 2 y 3 están de acuerdo en que sí se dedican un tiempo a trabajar 
la educación emocional en el aula y alaban que la Consejería de Educación de Educación y Cultura de la Región de Murcia proponga programas para llevar a cabo este contenido.

En uno de los casos se menciona un programa titulado "Volvámonos más cercanos", que surge a raíz del COVID-19 y cómo la pandemia ha afectado a nuestras rutinas y aprendizajes. En cambio el entrevistado número 4 considera que no se trabajan las emociones lo suficiente ni se presta espacio para resolver los conflictos emocionales de los niños y niñas quedando el trabajo de la educación emocional, en un segundo plano.

En cuanto a la pregunta número 2, hace mención a si el sistema educativo refleja como tal el aprendizaje de las emociones en las diferentes etapas educativas, todos los entrevistados están de acuerdo en que no aunque sí están implícitas de diferentes formas, como en las áreas curriculares del Decreto 254/2008 de 1 de agosto por el que se establece el currículo de la Educación Infantil en la Región de Murcia o a través de valores sociales y elementos transversales en el Decreto 198/ 5 de septiembre por el que se establece el currículo de la Educación Primaria en la Región de Murcia.

Respecto a la pregunta número 3, los entrevistados 1 y 4 consideran que la educación emocional no se comienza a trabajar desde el tejado de una casa ya que las emociones suelen trabajarse desde que surgen unos conflictos y no partiendo de una base inicial, como es el reconocimiento de las emociones. Además, el entrevistado número 3 considera que no se trabaja desde unos cimientos sólidos ya que solo se incide en ella cuando hay un conflicto y no de forma general y progresiva.

La entrevistada número 2 considera que hay una cierta subjetividad a la hora de comenzar la educación emocional ya que esta al no estar regulada de ninguna manera, se encuentra relegada y sometida a los procesos subjetivos de la enseñanza de cada docente así como

La pregunta número 4, hace referencia a si los sectores que intervienen en la educación de los alumnos y alumnas se coordinan entre ellos para que el discente pueda obtener un beneficio del sistema educativo. El entrevistado número 1 cree que no, que tanto inspectores como Consejería de educación nunca consultan a los maestros, y que los cambios continuos de legislación perjudican claramente al proceso de enseñanza. La entrevistada número 3 cree que también que no pero achacando el problema a la falta de formación en los docentes para tratar determinados contenidos relacionados con la educación emocional.

La entrevistada número 2 cree que en la mayoría de los casos sí, aunque la coordinación con la familia no siempre está garantizada. El entrevistado número 4 también considera que sí, sobre todo en proyectos, planes... pero no a la hora de trabajar la rama emocional.

La pregunta número 5, plantea si se respetan los intereses de los niños y niñas para llevar a cabo un proceso de enseñanza y aprendizaje positivo. 
El entrevistado número 1, cree que se intenta aunque a veces resulta muy difícil debido al elevado número de alumnos por aula, igual que opina el entrevistado número 4 , pero este destaca que si se sigue un modelo como el de las inteligencias múltiples de Howard Gardner, sería posible. La entrevistada número 2, cree que es posible a raíz de trabajar con metodologías activas como el Aprendizaje Basado en Proyectos o la Gamificación en el aula con el fin de aumentar el éxito escolar. En cambio la entrevistada número 3, cree que no se respetan ya que la enseñanza se limita a lo establecido curricularmente o se reduce a los libros de texto.

Respecto a la pregunta número 6, hace referencia a si hay consideración por parte de los docentes a la hora de trabajar la educación emocional. El entrevistado número 1 lo considera un tema primordial y explica que la Consejería de Educación y Deportes, ha establecido diferentes charlas, cursos... La entrevistada número 2 cree que sí, ya que diversos docentes han creado planes, proyectos... para trabajar la educación emocional en el aula. La entrevistada número 3 cree que depende de los docentes, aunque la mayoría de los casos sí abogan por esta temática, pero les falta tiempo y formación para su dedicación. Sin embargo, la entrevistada número 4, considera que los docentes se coordinan para trabajar proyectos que no son de educación emocional.

En cuanto a la pregunta número 7, señala si hay continuidad entre la Educación Infantil y la Educación Primaria a la hora de trabajar la educación emocional.

Los entrevistados número 1 y 4 creen que no. La entrevistada número 3 cree que sí pero solo en el caso de que se derive a los especialistas para trabajar algún problema concreto.

En cambio, la entrevistada número 2 cree que es un proceso complicado pero que los centros se esfuerzan por que haya esa continuidad.

La pregunta número 8, señala cómo deberían tratarse las emociones en la etapa de la Educación Infantil, el entrevistado número 1 y la entrevistada número 2, opinan que de forma transversal, a partir de las vivencias de los niños y niñas y con recursos que representen conceptos tan abstractos. En cambio la entrevistada número 3 y el entrevistado número 4, opinan que deben tratarte a través de diferentes rutinas y momentos diarios del aula.

En cuanto a la pregunta número 9, señala que no es el desconocimiento de profesores y maestros, lo que dificulta llevar a cabo programas relacionados con la educación emocional. Todos los entrevistados en general, opinan que es debido a la falta de organización curricular y de su programación. Pues muchas veces no hay tiempo para llevarlo a cabo.

Respecto a la pregunta número 10, hace referencia al por qué los entrevistados han decidido implicarse en la educación emocional, todos ellos afirman que tras considerar que es un "tema innovador", donde al estar "oculto" en el currículo hoy en día, hay diversos recursos, materiales... de fácil acceso. Así 
como la coordinación con el resto de profesorado y cómo estas metodologías innovadoras provocan en el alumnado un beneficio en su desarrollo personal, tras saber gestionar sus emociones.

La pregunta número 11, señala las diferentes metodologías que conocen o han llevado a cabo los entrevistados, así pues el entrevistado número 1 señala recursos y programas como "El monstruo de colores" y "El programa de Maria dolores Hurtado". La entrevistada número 2, señala el coaching educativo, que hace referencia a incluir a la familia para seguir trabajando las emociones en casa y el PNL, un programa donde se aboga por un lenguaje más positivo. La entrevistada número 3, señala el programa "Arco iris" de Ana Pintado. Por último, el entrevistado número 4, las inteligencias múltiples de Howard Gardner.

La pregunta número 12, hace referencia a que si se han retomado los aprendizajes de la Escuela Nueva, pero simplemente se les ha cambiado el nombre para hacerlos más atractivos. El entrevistado número 1, número 4, y la entrevistada número 2 creen que no, ya que las emociones es algo que se ha trabajado siempre, desde el campo de la inteligencia interpersonal e intrapersonal aunque no se le ha prestado la importancia que merecían. En cambio la entrevistada número 3 cree que sí, puesto que si a estas metodologías se les nombra de forma llamativa, surge un interés y actualización de forma positiva.

En relación a la pregunta número 13, hace referencia a cómo se introdujeron en la educación emocional, qué expectativas tienen respecto a ella y si han notado mejoría en su alumnado. Todos están de acuerdo en que han notado mejoría en su alumnado, respecto a la hora de expresar sus emociones, gestionarlas y resolver conflictos así como incluso aconsejar a sus propios compañeros. Respecto a su involucración y expectativas, depende de cada entrevistado. El entrevistado número 1, a través de una charla impartida a su hijo conoció esta metodología y sus expectativas se han cumplido. La entrevistada número 2, se introdujo en dicha metodología, buscando actividades para trabajar en su aula, aunque sus expectativas se han cumplido, consideraba que iba a crear una "pequeña revolución". La entrevistada número 3, considera sus expectativas cumplidas y se ha sumergido en la educación emocional, a través de su especialidad. Por último el entrevistado número 4, considera que aún debe cumplir la totalidad de sus expectativas, pero que gran parte de ellas sí se han cumplido.

Según la pregunta número 14, hace referencia a cómo era y es la implicación de los docentes en la educación emocional. Los entrevistados número 1 y 4 , consideran que ahora son más innovadores a la hora de implementar diferentes metodologías en el aula. Las entrevistadas número 2 y 3 , siempre han estado implicadas en la educación emocional.

La última pregunta, número 15, expone que serie de consejos darían los docentes entrevistados a futuros y futuras maestras. Todos los entrevistados, de forma general señalan que debe haber una formación de los docentes respecto a esta metodología, que debe ser continua y progresiva. Pues estamos 
rodeados de niños y niñas expectantes y debemos tener en cuenta sus características y adaptarnos a ellas para gestionar sus emociones.

\section{DISCUSIÓN DE LOS RESULTADOS}

Una vez analizados los resultados de las entrevistas, hemos extraído los siguientes aspectos a destacar:

En primer lugar, la mayoría de docentes entrevistados, consideran que la educación emocional es un aspecto que se trabaja en el aula y que la Consejería de Educación, facilita que este trabajo pueda implementarse en la escuela, a través de programas como el de "Volvamos más cercanos", que surge a raíz del COVID-19. Estos docentes pertenecen a la etapa de Educación Infantil, Educación Primaria y Pedagogía Terapeútica.

Sin embargo, el especialista en Educación Física, cuestiona que estos aspectos emocionales se trabajen desde su especialidad como se debería, reduciendo estos contenidos a momentos puntuales asociados a conflictos y no como un contenido transversal.

En segundo lugar, todos los entrevistados coinciden en que la educación emocional no está regulada en nuestro sistema educativo como tal. Sin embargo, aquellos docentes de la etapa de Educación Infantil y Primaria, sostienen que a pesar de ello, son un aspecto que se está implementando diariamente en el aula, dada la relevancia que tiene en la construcción personal y social de los niños.

Todos los entrevistados coinciden en que la enseñanza de las emociones debe comenzar desde la base, es decir, desde el reconocimiento de la emoción hasta ir adquiriendo progresivamente aspectos más complejos.

En relación a la coordinación de los distintos sectores implicados en la educación, los docentes de Infantil y Primaria y Educación Física señalan la falta de coordinación existente en muchas ocasiones y destacan la importancia de una adecuada coordinación de estos para favorecer el proceso de enseñanzaaprendizaje de los alumnos.

Unos consideran que el problema reside en la falta de consenso político y la necesaria coordinación y acuerdos fuera de los centros educativos, en donde también se escuche al profesorado. Además, consideran que en la escuela, con los medios ofertados, existe una adecuada coordinación entre los docentes pero no tanto, en relación a los aspectos emocionales a tratar sino en planes y proyectos de otra índole.

En cuanto a si se atiende a los intereses del alumnado, la mayoría de los entrevistados señala que, aunque se intenta, no se puede atender siempre a los intereses de los discentes, aportando razones como: las altas ratios o la rigidez del proceso de enseñanza que queda preestablecido por los libros de texto.

A pesar de la negativa de las respuestas, algunos aportan soluciones como el uso de metodologías activas en clase o la aplicación de teorías como las de Howard Gardner y las Inteligencias Múltiples. 
Aunque todos consideran la importancia de trabajar las emociones en el aula, los entrevistados sostienen que aún hay mucho por hacer ya que la enseñanza de estos elementos transversales, dependerá de la implicación del docente o de los planes y proyectos acordados en los centros. Por suerte, cada vez son más las personas interesadas en ello y ofrecen un espacio en el aula para la educación emocional. El docente de Educación Infantil, es quien tiene una percepción más positiva respecto a la aplicación de la educación emocional en las aulas actualmente.

Sobre la continuidad del trabajo de las emociones de Educación Infantil a Educación Primaria en torno al trabajo de las emociones, la mayoría de las respuestas coinciden en que no hay una continuidad. Sin embargo, la maestra de Educación Primaria, señala la importancia de la transición de una etapa a otra, alude a la legislación que regula esta transición y sostiene la preocupación de la mayoría de docentes porque así se produzca.

En relación a cómo debería trabajarse las emociones en el aula, las respuestas de todos los entrevistados, son muy semejantes: de manera transversal, a diario, en asamblea... Además, el maestro de Educación Infantil, propone diferentes formas y estrategias adaptadas a la edad y realidad de los niños como el semáforo emocional, pictogramas...

Cuando tuvieron que responder a si la razón para implementar programas emocionales es el desconocimiento del profesorado, todos los entrevistados sostuvieron que la falta de espacio y tiempo así como la importancia a otras materias más que a la educación emocional era el problema principal.

En relación a los motivos por los que se han implicado en la educación emocional, las respuestas son diferentes pero están muy relacionadas: la importancia de la construcción personal de los niños; agentes externos como la publicidad o los compañeros; la importancia que tiene para la especialidad etc. Además cada entrevistado propone respuestas diferentes sobre qué metodologías conoce para trabajar las emociones en el aula: cuentos infantiles, Coaching Educativo para implicar y formar a familias, PNL, "Programa Arcoíris" o Inteligencias Múltiples.

La pregunta acerca de si la educación emocional es algo innovador o ya se trabajaba en la Escuela Nueva, los entrevistados no coinciden en sus respuestas. El maestro de educación Infantil y el Maestro de Educación Física, sostienen que la educación emocional es un tema que no se le ha dado importancia a las emociones hasta ahora. Las maestras de Educación Primaria y Pedagogía Terapeútica, afirman que no es un tema innovador sino que se ha retomado de prácticas de la Escuela Nueva, incluso antes de esta.

Todos sostienen que han notado una mejoría al implantar educación de las emociones en el aula: expresión de emociones, regulación emocional etc.. Sin embargo, afirman que no ha notado mejoría por la falta de desconocimiento de su alumnado. Es probable que el maestro de Educación Física, haya tenido menos tiempo para estar con los alumnos y conocerlos más en profundidad. 
Tanto el Maestro de Educación Infantil como la Maestra de Educación Primaria, afirman que la educación de las emociones les ha cambiado a ellos también y les ha ayudado a comprender mejor a sus alumnos. Sin embargo, la maestra de Pedagogía Terapeútica sostiene que ella siempre ha aplicado estos conceptos y por ello, su percepción no ha cambiado. Además, el maestro de Educación Física, señala que él no ha cambiado personalmente sino su manera de enseñar.

Para finalizar, todos los consejos que nos aportan sostienen la formación continua del profesorado para trabajar la educación emocional en el aula, que será la base para hacer de los niños personas más felices y empáticas que sepan conocer, regular sus emociones y comprender las de los demás.

\section{CONCLUSIÓN}

Como se ha podido observar a lo largo de las entrevistas realizadas a diferentes maestros y maestras, de diversas especialidades, relacionadas con el ámbito de la Educación Infantil, optan por el trabajo necesario de las emociones desde edades tempranas. La gran mayoría cambia su percepción una vez que se implican en la puesta en escena de estos valores, tan importantes a trabajar y conocer desde edades tempranas. Es importante tener presente la legislación actual, pero también debemos conocer a nuestros alumnos y que ellos conozcan sus emociones y sepan resolverlas de la mejor forma positiva posible. Pues ello garantizará un adecuado proceso de enseñanza y aprendizaje.

Diferentes organismos implicados en la educación, como es la Consejería de Educación y Deporte de la Región de Murcia, consideran importante trabajar la educación emocional y han ideado un programa llamado "Volvámonos más cercanos", a raíz de la situación vivida como es el COVID-19. Aunque no sólo debe haber una pandemia para indicarle más importancia a algo que es esencial prestar atención, pues si una persona conoce y aprende a gestionar sus emociones desde edades tempranas, conlleva un desarrollo positivo en cuanto a capacidades como la física, cognitiva, afectiva y social y optará por un gran éxito escolar, como han mencionado los docentes entrevistados, que le han dado la importancia debida a la educación emocional. 


\section{REFERENCIAS BIBLIOGRÁFICAS}

Bach, E. y Darder, P. (2002). Sedúcete para seducir. Vivir y educar las emociones. Barcelona: Paidós.

Goleman, D. (1995). Inteligencia emocional. Barcelona: Kairós.

Gonzalez, M. (2020). Una microsociedad llamada aula.

López Cassà, E. (2005). La educación emocional en la educación infantil. Revista interuniversitaria de Formación del Profesorado, 3 (19), 153-167. Recuperado de URL: https://www.redalyc.org/pdf/274/27411927009.pdf

Rotger, M. (2017). Neurociencias y Neuroaprendizajes: las emociones y el aprendizaje, nivelar estados emocionales y crear un aula con cerebro. Córdoba: Editorial Brujas. 